\title{
Institutionalising Women's Interests and Accountability to Women in Development (Introduction)
}

\section{Anne Marie Goetz*}

\section{Introduction}

The phrase: 'getting institutions right' in the title of this IDS Bulletin refers to 'governance' concerns in current development policy discourses - concerns with understanding the relationship between patterns of development management, and development outcomes. These patterns institutionalise particular interests, particular interpretations of people's needs, and ways of responding to them. What might be involved in 'getting institutions right' for women is a question not often asked in governance debates. It should be. Gender and development (GAD) policy initiatives have, at least in principle, been accepted by the development establishment, yet the fact that social institutions and development organisations continue to produce gendered outcomes which can be constraining or outright disadvantageous for women means that we must interrogate patterns of administration and rule from a feminist perspective, and insist on accountability to women as a serious issue in development management and politics.

It is important to stress that institutions have not necessarily been 'right' for men either, shaping choices for them in limiting ways according to gender, class, and race in a variety of contexts. The focus here on getting institutions right for women, however, is meant to signal that a concern with gender justice should be a core value when analysing institutions and organisations and making proposals for change. The articles in this IDS Bulletin approach this project by analysing gendered patterns in the management of development organisations, and in their outcomes. They explore the ways in which characteristic organisational structures and procedures may produce accountability failures where women are concerned, the ways in which incentive systems may militate against the pursuit of women's gender interests in development, and the ways certain organisational cultures and cognitive orientations may undervalue women's perspectives and the expression of their interests. The articles also explore strategies for change, and alternative organisational arrangements. ${ }^{1}$

\section{Institutional contexts for development organisations}

It is helpful to make a conceptual distinction between institutions and organisations, where institutions are understood as sets of formal and informal rules which shape social perceptions of people's needs and roles, while organisations administer these rules and respond to needs. The economist Douglas North emphasises the role of institutions in limiting choice. They are 'humanly devised constraints' which reduce uncertainty and provide structure to everyday life (1990: 3).

Organisations are formed within the environmental constraint represented by institutions, but over time, they can have an impact on the institutional arena, changing underlying rules systems and incentive structures. Key institutional arenas for organisations include the state, the market, and the community, which are the contexts, respectively, for organisations such as the legal system, the administration, the military; firms and informal sector businesses; and the 'moral economy' of kinship organisations and families.

By limiting choice and controlling social relationships institutions make certain forms of behaviour and

\footnotetext{
*This article was first published in the IDS Bulletin Volume 26 Number 3 (1995) 'Getting Institutions Right for Women in Development' edited by Anne Marie Goetz. (c) Institute of Development Studies 1995
} 
their outcomes predictable and routine institutionalising them. The project for gendersensitive institutional change is therefore to routinise gender-equitable forms of social interaction and to challenge the legitimacy of forms of social organisation which discriminate against women.

Other definitions of institutions emphasise their role in generating experience. The sociologists Anthony Giddens and R.W. Connell suggest that by setting limits to, or boundaries around, social practice, including thought, institutions shape human experience, and personal identity (Giddens 1986; Connell 1987). The experience of gender difference, therefore, can be seen as a product of institutions, where it is the outcome of institutionalised patterns of distributing resources and social value, public and private power.

Gender also shapes or helps constitute institutions. The salience of gender relations for institutional forms has not, however, been obvious to many mainstream social scientists, partly because the production and reproduction of gendered inequalities are rarely made explicit in institutional ideologies and norms. In some institutional contexts, for example, the family, or the 'moral economy', the organising role of gender and generation is more evident. But there is an ideological and conceptual split between 'public' and 'domestic' or 'private' institutions, where a foundational principle is that public relations of production, exchange, and administration are indifferent to gender difference. This disguises the salience of gender divisions of labour, power, and desire as organising principles in these contexts (Connell 1987). A classic tenant of the Weberian view of bureaucratic organisation, for example, is that public bureaucracies are insulated from the social and political relations in which they are embedded, and in particular, abstracted from patrimonial, and by implication, patriarchal relations. But as Naila Kabeer notes: '[d] espite the separation of domestic institutions from the public domains of production and exchange, familial norms and values are constantly drawn on in constructing the terms on which women and men enter, and participate, in public life and the marketplace' (1994: 63). Though not often recognised by institutional or organisational theorists, gender is one of the 'root metaphors' (Morgan 1986) constituting human organisation.

An illustration of this is the way states have both assumed and construed women's identity for public policy as being conditioned by their social relationships as dependants of men. A large body of feminist scholarship about the welfare state in the West has illustrated a double standard of welfare provision for women and men. For example, assumptions about women's dependent and caring roles shape the nature of social security benefits they receive, and assumptions about masculinity have been built into state responses to men's welfare needs, as in 'Workman's Compensation' efforts to shore up eroding male egos when they are unable to support a family ( Fraser 1989; Nelson 1990; Pearce 1990). In the development context, a long history of colonial charity programmes and later, social policies, have contributed to the 'domestication' of women, targeting mothers and their 'dysfunctional' families (i.e. malnourished, poorly educated, or simply too numerous), and ignoring women's productive and political roles (Staudt 1987; Rogers 1980). Even efforts to integrate women to economic policy sectors evince striking gender differentials in the design and implementation of policy. Agricultural development policies rarely involve training and recruiting women extension agents, research in crops which women grow, and ensuring that market information and new production inputs reach women farmers. Instead, there are projects to enhance women's kitchen gardening or homesteadbased income-generating efforts. Such policies can reinforce the social system of women's subordination - they hardly provide women with an institutional alternative to dependence on the family, which employment rights or equitable participation in the market might do. They institutionalise a profound gender division in public policy clientship which reinforces notions that women and children's needs are rightly matters for private, male, provision.

Understanding institutions as frameworks for behavioural rules and as generators of experience contributes to understanding why it is that when new agents and orientations are introduced to institutions - such as women, and concerns with gender equity - outcomes can seem so little changed. Institutional rules, structures, practices, and the identities of the agents which animate them may continue to be primarily iterated to the political and social interests which institutions are designed to promote in the first place.

The familiar analogy between institutions and the 'rules of the game' in competitive sport (c.f. Schiavo- 
Campo 1994; Evans 1993) is helpful in expanding on this problem. 'Rules of the game' are adapted to the capabilities of the players; they challenge them, and allow for fair and manageable competition between particular categories of players. However, there may be completely new contestants who enter the game at a much later stage whose capabilities are not reflected in the parameters of the game. Like pygmies competing with the Harlem Globetrotters on a conventionally designed basketball court, they will be unable to win, because they cannot change some of the basic 'rules' - like the height of the net or the size of the court (Goetz 1994: 8). Most often, new participants have to adapt their behaviour to the existing rules. They may learn to win, but often at the cost of bringing their 'different' needs and interests to play - as when over-achieving managerial women become 'sociological males' (Kanter 1977).

An alternative, of course, is to opt out entirely - to create new forms of institutions and organisations. Women's organisations represent this kind of response. They are oriented to developing new structures and organisational cultures which reflect women's needs, interests, and behavioural preferences. It is no accident that women's organisations the world over often concern themselves with gender-specific problems which find unsatisfactory response from public or private institutions - problems such as sexual violence and personal physical security in the home. The articles in this IDS Bulletin by Lisa Pohlman, and Sheelagh Stewart and Jill Taylor, discuss women's organisations and ask whether women approach organisation and power in a different way from men. One observation they make is that these women's organisations continue, inevitably, to operate within the broader institutional contexts of the state, community, and the international environment for financing development operations, and are affected by these institutions in ways which impose dominant interests in development on their internal incentive structures and organisational forms.

\section{A gendered archaeology of organisations}

Most of the articles in this IDS Bulletin focus on development organisations, and in the process raise issues of relevance to the broader institutional contexts in which they are situated. Discussions of state bureaucracies and non-governmental organisations (NGOs) raise issues of relevance to the institutional contexts of the state and the community. A third institutional context is more difficult to define - it is what Connell calls 'the international state' (1990) - the arena for multilateral development organisations which operate across state boundaries, whose policies and development discourses are part of the institutional environment affecting individual states and NGOs. These organisations may be more or less affected by certain kinds of state (usually Western states), they are governed by different disciplines and ideologies, and they have more or less rigid bureaucratic hierarchies and degrees of internal democracy - contributing to some of the differences observed between the World Bank on the one hand and UNICEF or the United Nations Development Programme (UNDP) on the other.

The key to devising strategies to change organisations to enhance their receptivity and accountability to women whether as citizens of the state, participants in development programmes, or staff members in organisations, is to understand the gendered dynamics of decision-making and of organisational functioning. This requires attention to the way gendered internal structures and practices actually produce gendered outcomes and personnel who, whatever their sex, reproduce genderdiscriminatory outcomes. Following Connell (1987), the 'gender order' of institutions is made up of:

- Structures: the formal and informal rules which put boundaries around experience, and act as patterns of social constraint;

- Practice: the everyday behaviours and processes which give substance to structure, and which reproduce structure;

- Agents: the individuals who bring personal variants to their practices within structures.

Organisations put substance onto this framework. Their hierarchies, steep or flat, their degree of centralisation and bureaucratisation, their disciplinary foundations, and their rules, define their structures. These shape practice, as do organisational ideologies, mandates, missions, internal cultures, and their procedures. Together, these structures and practices produce incentive systems which affect the behaviour of individual agents within organisations, who also bring personal ideologies and behavioural patterns to their work in ways which may affect structures and practices. 
Before we start an analysis of the gendered nature of these organisational components we need to identify the gender interests which shape the institutional framework which embrace organisations. This is not a particularly easy task. Take the case of the state, which is the broader institutional framework for individual development bureaucracies, whether in the public administration or the non-governmental sector. Feminist analysts of the state run into the same difficulties as Marxist functionalists if they substitute gender for class and argue that the state is a 'general patriarch' (Mies 1986); an executive of men as a group, defending male interests. This suggests a homogenous and passive tool for a monolithic larger interest. It underestimates the complexity of the state, with its many different organisations with sometimes conflicting interests, offering differing prospects for feminist incursions. It obscures histories of women's struggles, and makes it hard to explain genuine victories achieved in women's interests - it is not helpful to describe these as always in some way serving men's longer-term interests (Gordon 1990: 16). Also, 'men's interests' as a gender are presumably just as difficult to identify 'objectively' as are women's, ${ }^{2}$ nor is the category of 'men', like 'women', valid as a universal. The historical record, however, does show that men tend to act, across divisions like class or race, more cohesively in defence of certain gender interests than do women, and they do so in ways which mean that public institutions help to forge connections between men's public and private power. In part, this owes to their longer occupation of public office and to their literal dominance of decision-making and decision enforcing. It also owes to the historical embedding of their needs and interests in the structures and practices of public institutions. Attention to the historical processes through which certain institutions come to promote male dominance and female dependence emphasises the importance of politics and contestation. ${ }^{3}$

Attention to gendered institutional histories also illuminates the gendered subtexts of apparently neutral organising structures, practices, and ideologies, to help explain why these prove so resistant to women and their interests. For example, in the West, studies of the history of the definition of the modern 'public' sphere, by Carol Pateman and others, have shown the effective exclusion of women from public citizenship in the sense that its definitional criterion was some form of 'independence' - defined in terms of the male experience, including property ownership, bearing arms, and 'employment' (Pateman 1988; Okin 1991; Gordon 1990: 20). The resulting gendered split between public and private came to institutionalise women's exclusion from the concerns and practices of public institutions. Inevitably, this exclusion means that values such as democracy, institutional procedures for ensuring participation, such as the vote, and processes underlining political legitimacy, such as securing popular consent, have a gendered subtext, defining women out of equal and effective public participation. In this IDS Bulletin, Katherine Fierlbeck's insightful analysis of the relationship between accountability, consent, and interest articulation reminds us of the ambiguities of 'consent' for women, where their presumed free consent to arrangements (such as marriage) which diminish their individual rights, obscures the role of institutional 'contexts of choice' in circumscribing their autonomy as freely choosing individuals. This comes as a timely warning in the context of governance debates. Democracy, participation, and accountability may not automatically allow for the expression of women's interests, divorced from changes in the institutions of private property or the labour market which might make women's participation more meaningful.

Focused feminist contestation at moments of structural or ideological change can open up important opportunities to inscribe women's interests in institutional arrangements. Three contributions to this IDS Bulletin discuss the work of 'femocrats' - women bureaucrats pursuing gendersensitive policy change in the state - at special historical moments for introducing women's interests to the state. Both in Chile, discussed by Georgina Waylen, and the Philippines, discussed by Ermelita Valdeavilla and Virginia del Rosario, a recent regime change from an authoritarian dictatorship to popular democracy has provided opportunities to institutionalise a place for women in the state, in the form of a new bureaucratic unit, in Chile, and a revitalised one in the Philippines. The broad legitimacy base of both new regimes, as well as the role of women in the struggles for democracy, has opened up new - though still uneasy - opportunity spaces for the expression and legitimation of women's concerns in state institutions. 
Continuing with our archaeology of organisations, we can move beyond an understanding of the gender interests in the histories of their institutional contexts to look at individual organisational histories. The original mission of an organisation will leave traces in organisational structures and cultures, and may be reflected in the thematic or sectoral categories for operations, in the boundaries set up between different organisational functions, in functional categorisations of staff, and the status implications these carry. Many bilateral aid agencies, for example, were once colonial or military supply organisations. This may leave institutional legacies in the form of steep and status-oriented command and control hierarchies, or cultures of adventurism and chauvinism at agency outposts. In the case of multilaterals, Elizabeth Harrison in this IDS Bulletin describes the Food and Agriculture Organization (FAO), whose original mission to increase agricultural output is reflected in a valorisation of strictly 'technical' approaches to agricultural development and in the uneasy position of 'non-technical' social scientists and gender policy advocates. Some international NGOs set up in response to the postSecond World War crisis in Europe may still have emergency supply units, where rapid responses to crises require sharp command and control relationships. These units may retain a high status, and their characteristic cultures may come to define the standard of valued, 'professional' behaviour within the organisation. Many originally small community-based NGOs in developing countries are currently 'scaling-up' into larger bureaucracies. A case study of organisational change in the Bangladesh Rural Advancement Committee (BRAC), one of the world's largest NGOs, is provided by Aruna Rao and David Kelleher in this IDS Bulletin. Here, the organisation's current identity as a development corporation, with a modern bureaucratic, relatively centralised, contract-based working environment, sits uneasily with the consensus-based, close and personalised nature of its original management structure when it was a small community development operation.

Organisations can be gendered in terms of practical, physical arrangements, in terms of management styles, organisational ideologies, and the expression of power. In practical terms, they may have come to be gendered according to the degree to which the interests and characteristics of the individual agents and social groups who originally peopled these organisations reflect gendered physical and social needs and capabilities. Men's literal, physical monopoly of public organisational space means that everyday work patterns come to be structured around their physical needs and capabilities - in particular, their capacity to achieve relative liberation from child care and domestic responsibilities. This will be reflected in the lifestyle patterns which accompany particular career trajectories, and will obviously constrain women who cannot guarantee the same quantities of time and emotional and physical energies to organisations as men can. This will produce a gendered structuring of physical space and of time (working day and life cycle/career time) in organisations.

Some feminist analysts of bureaucracies, such as Kathy Ferguson, argue that this literal male dominance is embedded in distinctive features of bureaucracy such as the valorisation of instrumental rationality, top-down command and communication systems, specialisation, as well as aggressive, goaloriented styles of management. The suggestion that these represent innate sexual characteristics is highly contentious, as indeed is its corollary - the suggestion that these features of administration necessarily exclude positive outcomes for women. Sheelagh Stewart and Jill Taylor give an example in this issue of working with the police in Zimbabwe to promote better responses to problems of domestic violence. In spite of serious problems with the masculinist culture of the police, the centralised structure of the police force, along with its strong logistical capability and extensive network of outposts, was a positive advantage in expanding the coverage of the project and ensuring a uniformity in response. Rigid bureaucratic structures, nevertheless, will have implications for the experiences of women staff in organisations, who may favour different styles of management, decision-making, and interpersonal interaction, but may find these preferences penalised.

The ideologies and disciplines which animate organisations can institutionalise strong gender biases. Staudt's analysis of international development agencies shows that organisations based on disciplines of economics or agricultural economics have excluded gender difference as relevant to their focus on efficiency and growth. Organisations oriented to social and human development concerns 
have proven much more open, recently, to the inclusion of gender issues (1994: 82-4). Still, it is not impossible to imagine a feminist economics, and on the other hand, the history of organisations such as the World Health Organization (WHO) or UNESCO demonstrate that a commitment to human development does not automatically include a commitment to gender equity or attention to women's gender-specific needs. It would seem there is no substitute for the injection of an explicit concern with gender equity, and the exercise of leadership or vision in women's interests. This may come with the presence of more women staff, although this is debatable, and will be discussed shortly. What it certainly implies is contestation, in particular, a struggle to valorise and legitimate women's perspectives.

Treating women's perspectives as valid and legitimate, however, is undermined by the gendered nature and expression of power and authority in organisations. The greater significance assigned to male achievements and forms of expression, as a consequence of their near-monopoly over power in organisations, is reflected in organisational value systems, in the gendering of particular skills, permitted behaviours, and symbols of success or failure. The contribution of women both individually and as a group can be devalued by invoking the symbolic significance of the public-private divide to associate their presence and affectivity in the organisation with their private identities. Sex-typed tasks signal this, but its most insidious expression is the problem of sexual harassment, which deeply undercuts the identity and effectiveness of women as autonomous and equal public agents. The gendered expression of power and authority in organisations, then, will affect the prospects for the development of leadership in the interests of gender equity, especially if it is women who are promoting alternative visions of organisational missions and management. It will also affect prospects for changing the nature of power and the way it shapes organisational structures and cultures.

To summarise, what has been discussed are gendered structures and practices in organisations, as they are expressed through gendered accountability and incentive systems, gendered cultures and processes, gendered expressions of power and authority, and gendered patterns of organising space and time.

\section{Accountability to women across institutional contexts}

The articles in this IDS Bulletin explore the interaction of gendered structures, practices, agents, and outcomes within particular organisations. Some articles draw out the relationship between gendered patterns in particular organisations and their institutional environments. Brooke Ackerly's contribution discusses how rural credit institutions in Bangladesh both work within and challenge community, market, and familial constraints on women's financial autonomy. Her exploration of women's degree of knowledge about the accounting for the investment activity funded by their loans (which she takes as one proxy for empowerment) shows that organisations differ in the clarity with which they challenge the informal institution of male control over family resources. This has implications for programme design and incentive systems, where incentives oriented to building women's market knowledge may contribute more directly to empowerment than incentives oriented to credit performance. Elizabeth Harrison's article shows how confusion about, resistance, or indifference to the relevance of gender issues within the fish-farming sector of the FAO can be reinforced at the level of national institutions such as agricultural extension systems by the lack of awareness of gender issues and the lack of women extension agents, and at the community level by a reluctance to undermine the 'moral economy' with the suggestion that there are significant gender differences or conflicts.

Nüket Kardam's article provides a framework for situating inter- and intra-organisational issues in a broader, cross-institutional context. She stresses the importance of understanding divergent gender politics and institutional incentives which operate in three important contexts: the political context, the organisational context, and the cognitive context. These will affect incentive structures of interacting agents in development: NGOs, the state,

multilaterals, and target populations. Where performance incentives respond to different political, organisational, and cognitive imperatives, accountability failures result. Veena Siddarth provides a perspective on this problem as it has developed in the context of NGOs pressuring the World Bank for policy changes. Gender issues have been sidelined in this process for a variety of reasons having to do with the disjunctive incentive systems and operational contexts of NGOs and the World Bank. Interestingly, 
NGOs have been more successful at lobbying their own governments for gender-sensitive policy change, perhaps because of coinciding political incentives stemming from domestic constituencies.

Organisations do not operate in vacuums, and accountability and incentive systems are shaped by the broader institutional environment. The near-global mood of neo-liberalism in the management of public institutions, with the imposition of commercial contracts for services which may be hard to measure in monetary terms (such as counselling victims of domestic violence, consciousness-raising work, community care, or academic reflection) has meant the introduction of new principles, relationships, and incentives which can marginalise many concerns and projects associated with women's empowerment. Stewart and Taylor's article details the bureaucratic and hierarchical relationships introduced to a Zimbabwean women's organisation when it began receiving foreign funding. The new preoccupation with financial accountability meant a shift in accountability towards funders, away from the organisation's primary stakeholders, its female membership. Rosamund Ebdon details a case from Bangladesh where large credit NGOs, in the process of 'scaling-up' partly in response to donor funding opportunities, appear to experience a shift in incentives and objectives away from empowerment, to credit performance.

\section{Interest representation}

Issues of accountability raise questions of representation and of the nature of the interests which are institutionalised in different organisations. These issues are discussed in Katherine Fierlbeck's article, which focuses on the contexts of choice in which women determine their political interests. She highlights the importance of determining whether the choices institutions create for women are gender-constrained, in the sense that they create environments which embed women's perceptions of their own interests in a narrow range of gendered subjectivities. The importance of ensuring meaningful conditions for choice - which include material and political equality - puts paid to sunny assumptions that more democratic governance will automatically enhance accountability to women, without attention to the contexts in which women consent to particular distributions of social and political power.

Fierlbeck's article also relates to the problem of identifying women's gender interests, which is central to assessments of the gender sensitivity of organisational responses to women. Maxine Molyneux has provided a practical guide to this question by distinguishing between women's (and men's) practical gender interests which arise from their lived realities as socially gendered individuals, and strategic gender interests which are deduced from an analysis of women's subordination and which are oriented to transformation of the relations between the sexes (1985). Anna Jonasdottir situates the discussion of women's interests in the context of feminist institutional change efforts, by distinguishing between women's interests in gaining 'simple access' to institutions and establishing a 'controlling presence' within them, as women acting in a corporate, not merely numerical, sense (1988). This does not necessarily point the way to ensuring that institutional change is occurring in ways which promote women's strategic interests in changes in gender relations, as it is not impossible to imagine a non-feminist corporate expression of women's interests - the successes of the anti-feminist women's lobby in the USA in challenging abortion rights or undermining the Equal Rights Amendment are indicators of this possibility.

This makes it inescapable to hold, if only as a temporary analytical device, a feminist notion of women's interests in mind, but one which is produced out of specific historical and cultural contexts. This is obviously not straightforward, and the implications of cultural differences for the meaning of feminism (even if there were one meaning of feminism) have been chastening. Feminist theorising has acknowledged and embraced the importance of social difference as a source of variation in women's life experiences and hence in their political perspectives. The problem with cultural identity politics for feminist capacities to make judgements about gender justice is partly that it raises the spectre of relativism. Also, in the context of celebrating cultural difference, there can be a tendency to conflate social or cultural identity with political opportunity and choice, a point made in Fierlbeck's article. This is a form of conceptual slippage which has very conservative implications - it comes back to a problem of associating a rather limited and sex-typed range of political and social interests with women.

\section{Institutionalising women's interests in the state}

There is a need to work both with and beyond context-restricted perceptions of interest to establish 
what might be called a strategic presence in policymaking. This strategic presence is about interest representation at the level of the state, an issue raised in Waylen's discussion of the representation of women's interests in the process of re-democratisation in Chile, and in two articles on the national 'machinery' for women in the Philippines, by Valdeavilla and del Rosario. These articles address the tensions between formal systems of interest incorporation and representation, and the generally weak social and political impact of women in the absence of an institutionalised form of representation in the state. The former often leads to co-optation. The latter, women's grassroots activism, can be effective at the local level, as in Chile, but tends to be oriented to organisational forms which do not translate well into effective participation in broader political processes. The Philippine case illustrates one of the most effective examples of national women's machinery in terms of institutionalising a place for women to express interests at policymaking levels. Even here, however, accountability and representation remain key problems, as expressed in difficulties in cultivating a sustained dialogue with the women's movement. The two articles on the Philippines also traced a range of characteristic patterns in the management of public institutions which undercut the potential for mainstreaming gender concerns. These include the high boundaries maintained between different sectors in public administration, conflicting and competing sectoral concerns, and problems of isolation and marginalisation of gender policy representatives.

\section{Women in organisations}

Are women civil servants, politicians, and development agents effective representatives of women's interests? This is a question addressed in Shirin Rai's study of women MPs in India. She suggests that a range of cross-cutting forms of institutional loyalty - to class, caste, and to the institution in question - as well as the general absence of mechanisms for dialogue with women constituencies - limit the potential for genuine representation of or leadership in women's interests. The intense personal pressures faced by women in these institutions encourages conformity to more 'masculine' and elitist interests. These personal pressures include the tension of managing professional and domestic labour obligations, and the resistance and hostility of male colleagues.
Confronting institutionalised masculinism in these contexts is risky, especially when women are in such a dramatic minority and lack structured external support such as might come from women's organisations.

One of the articles in this issue suggests that efforts to promote women's leadership capacities can result in the development of 'feminist' perspectives on the organisation - understood as a critical perspective on gender inequality. Marion Macalpine's discussion of a management development programme for women bureaucrats shows that women's awareness of gender issues in their working environments was raised; they moved from collusion to opposition, and developed strategies for mutual support within their organisations. Whether this will result in structural changes to the organisation of power and to management cultures remains an empirical question - there are still too few cases of organisations dominated by women in leadership positions to permit generalisation.

\section{The analytical and practical challenge: how do we get institutions right for women?}

There are several recurring analytical and conceptual dilemmas in feminist approaches to institutional change - what Aruna Rao has called 'de-institutionalising male privilege'. These dilemmas are addressed in various ways by the IDS Bulletin articles, and can be framed as questions, listed below.

\section{What would feminist or gender-sensitive institutions look like?}

Is hierarchy and bureaucracy necessarily antithetical to gender-sensitive environments internal to organisations and to feminist outcomes? Would feminist or more humane institutions be more participatory and inclusive, based on more consensual decision-making? Studies of NGOs which promote participatory democracy, non-hierarchical decision-making, and minimisation of status differences have not found any necessary correspondence between alternative organisational forms and feminist attitudes and outcomes. Siddarth's article in this IDS Bulletin hints at a nearsystemic lack of vision about - or at least, a reluctance to champion - gender issues amongst the NGOs she discusses. In other words, management democracy alone does not add up to an institutional comparative advantage in the absence of objectives prioritising gender equity. 
Would more women staff in development organisations change processes and outcomes?

Do women have a different relationship to power than do men - would they develop a new 'women's agenda'?

Lisa Pohlman's article discusses the tensions experienced by women development leaders when dealing with power issues in management, even in all-female environments. She finds that women development leaders in Bangladesh express ambivalence about exercising power, but are nevertheless pioneering new approaches to decisionmaking and power sharing.

To explore the question of whether women approach public organisation membership differently from men, more still needs to be known about women bureaucrats and agents in development organisations. As many of the articles in this IDS Bulletin suggest, as long as women remain in a minority in these contexts, it is very difficult for them to develop any potential for performing as advocates in women's interests given the pressure to respond to dominant organisational incentives. This underlines the importance of strategies for networking to build up internal power and support blocks, and to connect to external sources of support.

Perhaps the best ideal guide for determining whether institutions are gender-sensitive would be an examination of whether the choices they produce both for their personnel and their clients are not gender-typed.

This raises another, central question:

\section{On what basis can we assess whether institutions have been accountable to women? What}

constitutes evidence that the choices institutions create for women are not gender-typed? This raises questions about women's interests which were discussed earlier.

Ideally, organised constituencies of women in civil society putting pressure on the state or supporting changes within organisations in other institutional contexts should make the question of women's interests in the development process clear. Interest articulation and aggregation are processes which ideally insert organised preferences into political systems and institutional contexts. Often in formal politics, women's approaches to interest articulation and aggregation are not recognised as distinctly political forms of organising. For example, certain characteristic patterns of women's mobilisation in Latin America show that women may choose relatively weak organisational forms, such as informal neighbourhood groups, to address their immediate problems like healthcare, sanitation, or cash-flow crises in individual households. These groups, which aggregated into popular protest movements with an undeniable effect on politics, evaporated in countries like Chile with the resumption of formal party politics because their weak organisational forms did not represent a form of interest articulation institutionally recognised in the arena of political competition.

Two implications arise from this. First, given the structural problems in mobilising a women's constituency to support the efforts of feminist policy advocates within states and development

organisations, it is important to build on the political potential of strategies women may employ to satisfy immediate survival needs, to find new forms of selfexpression and identity, and to resist oppressive state practices, by recognising these as forms of political interest expression. Second, as Jaquette suggests, it is also important to acknowledge the limits of these strategies in broader political terms. Since these local struggles and methods transfer so poorly to more complex political arenas, there is a need for concerted efforts to introduce processes of articulating and aggregating women's interests in important political arenas like parties and trade unions. This again, however, raises the central problem of this IDS Bulletin: the difficulty of institutionalising women's interests in public institutions - and this has been a particular problem where women have attempted to introduce their concerns to institutions structured around classbased forms of political expression. Perhaps one effective strategy in this context would be to encourage men to recognise their gender interests and the need to redefine them in a more humane, gender-equitable way. This would support the process of gaining legitimacy for notions of gender interests in politics.

In the end, as Nelson and Chowdhury (1984) suggest, probably a good guide to assessing the interests expressed in institutions is an analysis of the gender 
ideologies implicit in institutional outcomes. Gender ideologies include personal theories about power and agency, and express views on the extent of desired individual and social change. The key would be to interrogate these ideologies for the potential they display for transforming the unequal distribution of resources, social value, and agency between women and men.

Clearly, 'getting institutions right' for women in development entails feminist political activism across all social institutions and within individual

\section{Notes}

1 Most of the articles in this IDS Bulletin were presented at a workshop at the Institute of Development Studies (IDS) in November 1994. Participants came from a range of different organisations and institutional contexts. One objective was to achieve a degree of crosspollination between theorists and activists, and the articles in this IDS Bulletin reflect the variety of perspectives offered by academics, management specialists, civil servants, and members of development organisations, many of whom offer 'insider' accounts of strategies to get

\section{References}

Block, F. (ed.) (1987) Revising State Theory: Essays in Politics and Postindustrialism, Philadeliphia: Temple

Chowdhury, Najma and Nelson, Barbara J. with Carver, K., Johnson, N. and O'Loughlin, P. (1994) 'Redefining Politics: Patterns of Women's Political Engagement from a Global Perspective', in B. Nelson and N. Chowdhury (eds), Women and Politics Worldwide, New Haven: Yale University Press Connell, R.W. (1987) Gender and Power, Cambridge: Polity Press

Dahlerup, Drude (1988) 'From a Small to a Large Minority: Women in Scandinavian Politics', Scandinavian Political Studies 11.4: 275-98

Evans, Alison (1993) "'Contracted-out": Some Reflections on Gender, Power, and Agrarian Institutions', IDS Bulletin 24.3

Evans, P., Rueschemeyer, D. and Skocpol, T. (1985) Bringing the State Back In, Cambridge: Cambridge University Press

Ferguson, Kathy (1984) The Feminist Case Against Bureaucracy, Philadelphia: Temple University Press organisations. As Bernard Schaffer has shown, drawing on post-modern social theory, administration is not a technical instrument but a political situation - composed of knowledges and social relationships which encode a history of contestation (1984). What the above unravelling of organisations shows is that there are many different points for positive interventions, but the social relations involved in public administration cannot be settled just by getting a structural blueprint right - in the end, it is a matter of political struggle.

their own organisations 'right' for women. I am grateful to the participants for their comments on this introductory essay.

2 For discussions of women's gender interests, and in particular, whether 'objective' or 'strategic' interests can be identified for women as a gender, see Molyneux (1985), Jonasdottir (1988), and Fierlbeck, in this IDS Bulletin.

3 It suggests a model of the state such as that proposed in 'state-centred' approaches, cf:: Skocpol and Amenta (1986), Evans et al. (1979), or Block's (1987) conflict model of the state.

Fraser, Nancy (1989) Unruly Practices: Power, Discourse, and Gender in Contemporary Social Theory, Cambridge: Polity Press

Giddens, Anthony (1986) Sociology: A Brief But Critical Introduction, London: Macmillan

Goetz, Anne Marie (1994) 'The Politics of Integrating Gender to State Development Processes', mimeo, Geneva: United Nations Research Institute for Social Development (UNRISD)

Gordon, Linda (ed.) (1994) Women, the State, and Welfare, Wisconsin: University of Wisconsin Press Jaquette, Jane and Staudt, K. (1988) 'Politics, Population, and Gender: A Feminist Analysis of US Population Policy in the Third World', in K. Jones and A.K. Jonasdottir (eds), The Political Interests of Gender, London: Sage

Jonasdottir, Anna K. (1988) 'On the Concept of Interest, Women's Interests, and the Limitations of Interest Theory', in K. Jones and A.K. Jonasdottir (eds), The Political Interests of Gender, London: Sage Kabeer, Naila (1994) Reversed Realities, London: Verso 
Mies, Maria (1986) Patriarchy and Accumulation on a World Scale, London: Zed

Molyneux, Maxine (1985) 'Mobilization Without Emancipation? Women's Interests, the State, and Revolution in Nicaragua', Feminist Studies 11.2: 227-54

Nelson, Barbara J. (1990) 'The Origins of the Twochannel Welfare State: Workmen's Compensation and Mothers' Aid', in Linda Gordon (ed.), Women, the State, and Welfare, Wisconsin: University of Wisconsin Press

North, Douglas (1990) Institutions, Institutional Change and Economic Performance, Political Economy of Institutions and Decisions, Cambridge: Cambridge University Press

Okin, Susan Moller (1991) 'Gender, the Public and the Private', in D. Held (ed.), Political Theory Today, Cambridge: Polity Press

Pateman, Carole (1988) The Sexual Contract, Cambridge: Polity Press

Pearce, Diana (1990) 'Welfare is Not For Women: Why the War of Poverty Cannot Conquer the
Feminization of Poverty', in Linda Gordon (ed.), Women, the State, and Welfare, Wisconsin: University of Wisconsin Press

Rogers, Barbara (1980) The Domestication of Women, London: Tavistock Publications

Schaffer, Bernard (1984) 'Towards Responsibility', in E. Clay and B. Schaffer, Room For Manoeuvre, London: Heinemann

Schiavo-Campo, Salvatore (ed.) (1994) Institutional Change and the Public Sector in Economies in Transition, World Bank Discussion Paper, Washington DC: World Bank

Skocpol, T. and Amenta, E. (1986) 'States and Social Policies', Annual Review of Sociology 12: 131-57

Staudt, Kathleen (1994) 'Technical Assistance and Women's Lives', mimeo, Geneva: UNRISD

Staudt, Kathleen (1987) 'Women, Politics, the State, and Capitalist Transformation in Africa', in Irving L. Markovitz (ed.), Studies in Power and Class in Africa, New York: Oxford University Press 